\title{
Global FDI Convergence Patterns?: Evidence from International Comparisons
}

\author{
Constantina Kottaridi \\ University of Peloponnese \\ Dimitrios D. Thomakos \\ University of Peloponnese
}

\begin{abstract}
In this paper we examine, for the first time to the best of our knowledge, the issue of convergence in Foreign Direct Investment (FDI) for a sample of countries representative of the world economy. We distinguish between groups of countries so that we can better understand differences attributed to specific developmental stages and different institutional and regional characteristics. The results of our analysis can be seen as an attempt to evaluate the validity of the New Economic Geography (NEG) theory which predicts a "core-periphery" structure of international production at intermediate trade costs. Our econometric methodology utilizes panel unit root tests, which have previously been used in similar studies, but also appropriate dynamic panel regressions to correctly assess the magnitude of the convergence coefficient. Furthermore, we provide a simpler derivation for an equivalent estimable equation to the one used in past convergence studies. Our overall results point toward convergence tendencies, contrary to a "coreperiphery" pattern. We discuss our results in the context of the relevant literature, along with their policy-making implications for transnational, national and regional investment strategies.
\end{abstract}

- JEL classification: F21, F41, R11

Corresponding author: Dimitrios D. Thomakos, Department of Economics, School of Management and Economics, University of Peloponnese, Tripolis 22100 Greece, E-mail: thomakos@uop.gr, fax: +302710-230139.

Constantina Kottaridi, Department of Economics, School of Management and Economics, University of Peloponnese, Tripolis 22100, Greece. E-mail: kottarid@uop.gr ○2007-Center for International Economics, Sejong Institution, All Rights Reserved. 
- Keywords: Convergence, Foreign direct investment, New economic geography

\section{Introduction}

Globalization forces and massive restructuring of production during the last two decades have revived the dialog on the allocation of Foreign Direct Investment (FDI) across regions. FDI has nowadays emerged as a potentially distinct form of capital that can contribute in many ways in the development trajectory of a host nation. Thus it is an issue of particular importance for researchers and policy agents. ${ }^{1}$

FDI is claimed to be a transfer medium for technology and skills: it conveys new production methods, advanced products, trained and skilled personnel and new management techniques. Thus, it is considered a vital source of economic development of laggard economies and a force that may boost growth in already advanced ones. In the context of the New Growth Theory (NGT), capital is considered to incorporate technological progress and, under this perspective, accumulation of physical capital generates a process of sustainable growth. High growth rates permit factor abundant, rich nations/regions to further strengthen their advancement, especially if they employ their resources in R\&D activities. On the other hand, poor regions will lag behind unless they succeed in raising their technology level and move to a higher growth level. The above predictions are particularly signicant within the context of the "convergence" debate among countries within Regional Unions such as the EU or even among sub-regions within the same country-state. Massive FDI flows between similar, in economic terms, countries already evidenced from the early eighties, gave rise to the New Economic Geography (NEG) in the decade of nineties which combined scale economies with trade costs to explain agglomeration of production in certain locales. The main implication of NEG rests on the assumption that regions are likely to differentiate into a rich 'core' and a poor 'periphery', creating virtuous cycles for advantageous regions and vicious cycles for the less advantageous ones. NEG theory may be perfectly combined with NGT and provide us insights regarding income distribution which is the ultimate concern of all policy-makers.

The main contribution of this paper is that it examines, for the first time to the best of our knowledge, FDI patterns worldwide, assessing the validity of NEG

\footnotetext{
${ }^{1}$ International production is presently carried out by at least 61,000 Multinational Corporations (MNCs)
} with over 900,000 foreign aliates standing for an FDI stock of approximately $\$ 7$ trillion (WIR, 2004). 
predictions by testing whether there is any evidence of FDI convergence. Although the bulk of FDI is taking place between already advanced countries, emerging and developing economies are increasingly receiving attention as vital hosts for foreign production due to their comparative advantage in recourses and labor costs. In addition, recognizing the beneficial role of FDI, countries are competing for attracting foreign investors providing a number of financial and other incentives such as tax allowances, preferential treatment etc. Under this perspective, we have witnessed a rapid expansion of foreign activities in the new EU member states (accession countries) of Central and Eastern Europe (CEE), the Newly Industrialized Countries (NICs) of South-East Asia but even in some low-income countries of Africa and Latin America. This triggers our interest to investigate potential FDI convergence trends around the world. We employ additional econometric methods in estimating the speed of convergence, besides the standard panel unit root tests used almost exclusively in the literature, thus providing a measure of robustness for our results. Finally, we provide a simper derivation for an equivalent estimable equation to the one used in the convergence literature.

The rest of the paper is organized as follows: in section 2 we discuss the FDI convergence question this paper is trying to address, and review the relevant literature. In section 3 we describe the data we use and the methodology we follow for assessing convergence. In section 4 we present the results of our empirical analysis and, nally, in section 5 we oer some concluding remarks. All tables are provided in the appendix at the end of the paper.

\section{FDI convergence: why should we care?}

The literature on FDI is vast and extends from international business and strategic management to trade-related theories and growth models. Economic theory has traditionally explained differences in production structures based on comparative advantage, i.e., on underlying differences in relative factor endowments, geography or technology, which differentiate regions. Nevertheless, it became obvious in the early eighties that even regions with similar characteristics come out to have very distinct production structures. This gave rise to the New Trade Theory (NTT) (Krugman 1979, 1981; Markusen 1984; Helpman 1984; Helpman and Krugman 1985; Horstmann and Markusen 1987, 1992; Markusen and Venables 1998, 2000), which deprived the standard neoclassical diminishing returns in production and talked about imperfect competition with constant or 
increasing returns as a result of spillover effects. The focal point of NTT revolves around differences in market size and market access of economies. In this respect, it shares much with traditional trade theory.

In the early nineties, Krugman (1991) pioneered the NEG theory, extending NTT by combining increasing returns with trade costs to explain the agglomeration of foreign production in specific milieus that formed clusters of activities principally across developed economies. NEG models were then elaborated in later works in Krugman (1993, 1995), Venables (1996), Martin and Ottaviano (1996) and Ottaviano and Puga (1997) among others. With falling trade costs, there is a tendency for production to settle near large markets, however, "the possibility that the competitiveness of the peripheral countries will either improve or worsen with the fall in trade costs represent two fundamental ambiguities..." (Soci, 2003, p. 645). Notwithstanding that globalization forces shape a borderless world where the transfer of capital, goods, services and people is easily taking place, it is notable that some regions are more advantageous in hosting foreign operations and therefore reap the benets associated with these. How is this explained? NEG pinpoints the role of cumulative causation mechanisms that pool activities together forming agglomeration zones. These mechanisms include labor migration, forward and backward linkages, technological externalities in factor accumulation, which create pecuniary externalities in production.

Under such a cumulative causation perspective, a small initial asymmetry or even a "historical accident" may lead to large differences between regions initiating virtuous and vicious cycles. To see how cumulative causation works, we only have to think of spillover effects taking place in host markets by foreign presence through the emerging interaction with host agents. Take for example a foreign investor that uses intermediate products from local suppliers; the increased competitiveness and requirements of the investor induces domestic suppliers to advance their operations and function more effectively in order to meet their customer's needs. By doing so, more foreign investors would be willing to locate there in order to benefit from well-suited upstream industries. Consequently, the domestic market accrues benefits constantly and attracts even more activities and so on and so forth. This is the virtuous cycle mentioned above.

Parallel to NEG but predicting the same "core-periphery" pattern, stands the NGT or alternatively Endogenous Growth Theory (EGT) or Schumpetarian Growth Theory (SGT). The emergence of NGT is rooted again in the decade of eighties however from different empirical observations. In particular, it was evidenced that 
some countries were able to sustain increasing growth rates whilst others were stagnating. This came at odds with the neoclassical perception that predicted that all countries would tend towards the steady state in the long run with poorer countries growing faster than the rich ones. This is based on capital's diminishing returns, which induces lower marginal productivity as it grows. Romer (1986), Lucas (1988), Rebelo (1991), Grossman and Helpman (1991), Aghion and Howitt (1992) viewed capital as incorporating technological progress, hence, accumulation of physical capital generates a process of sustainable growth. In this respect, factor abundant, rich countries/regions may strengthen their advancement continuously, whilst poor regions may be deemed to lag behind unless they succeed in raising their technology level and escape the poverty 'trap' moving to a higher growth level. Thus, the possibility of income divergence rather than income convergence was opened up and raised serious concerns to policy makers. In what regards the role of FDI in the growth prospects of nations and regions, evidence favors the enhancing role of FDI especially in more advanced economies (De Mello, 1996, 1997; Borenstein et al., 1998; Zhang, 1999; Braconier et al. 2001; Bengoa and SanchezRobles, 2003; Kottaridi, 2005).

Both NEG and NGT are particularly relevant in the context of economic integration. Disentangling trade barriers and free movement of goods, capital and workers, reinforce agglomeration tendencies and divergence patterns although existing theory is not certain about the final outcome. Economic integration creates what Fujita and Thisse (1996) call "putty clay" geography: there is a priori great exibility on where particular activities locate but they become rigid once spatial differences take shape. Krugman (1991) from the point of NEG predicts that for intermediate trade costs, agglomeration is certainly endorsed and forces of dispersion can only be set in motion for very high or very low trade costs. From the growth perspective, it is claimed on the one hand that free trade (including knowledge transfer) and factor mobility should yield a growth bonus to both rich and poor nations (Rivera-Batiz and Romer, 1991). On the other hand, Lucas $(1988,1990)$ claims exactly the opposite: factor mobility induces human capital to ow to regions with higher wages, i.e., the rich regions. In turn, the inflow of human capital in the region increases its stock of knowledge, creating thus knowledge spillovers. Given increasing returns to production, wages will not drop as in the neoclassical framework, hence rich places are further benefited and poor places fall behind. ${ }^{2}$

${ }^{2}$ For a theoretical discussion on wage inequality between the 'North' and the 'South' based on the formation of MNEs and R\&D activities, see Dinopoulos and Segerstrom $(2004,2005)$. 
Testing for the effects of integration, Hanson (1997a, 1997b, 1998) examined the US-Mexican case and found that integration with the US has shifted Mexican industry away from Mexico city towards states with good access to the US market. Brü lhart and Torstensson (1996) developed and tested a model for the EU within the framework of monopolistic competition and concluded that increasing returns industries tend to be highly localized, concentrated in central EU countries that have good access to large markets. However, they gave support to a U-shaped relationship between the degree of regional integration and agglomeration: in early stages of European Integration activities (of larger scale economies) were more concentrated to the core of the EU however, concentration in the core has fallen in the 1980s. Furthermore, Quah (1996) examines income inequalities across NUTS II EU regions and provides evidence for the importance of spatial spillovers, which he proves that matter more than national characteristics.

On the grounds of the above discussion, we may allege that both in what regards economic integration areas such as the EU and within the broad context of globalization, there is no complete factor mobility neither fully free trade, i.e., "borders-both geographical and cultural-appear to matter" (Soci, 2003, p. 650). Capital market restrictions, barriers to entry and most importantly, difficulties in labor mobility are evidenced facts.

Agglomeration of production as predicted by NEG regards different levels of aggregation, from small-scale agglomerations of finely defined sectors to largescale agglomerations that permeate country boundaries (Ottaviano and Puga, 1997). Looking at the pattern of FDI spread worldwide, it is apparent that it constitutes a dynamic procedure that evolves over time following economic, political and technological changes. Hence, some countries that used to be very attractive may have lost their alluring characteristics on other previously unattractive hosts. The increasing globalization tendencies and technological developments alter inevitably the comparative advantage of countries and regions, thus, induce an endless relocation of international production. Under this perspective, scholars have largely evaluated and continue to do so, the determinants and effects of FDI on distinctive recipient economies drawing valuable policy considerations to policy-making circles, followed by informative suggestions on improving domestic markets and magnetizing foreign production.

This paper's focus hinges on an inspiring methodology to check the bi-polar space referred to above at a large scale, i.e., FDI capital stock at the country level. The analysis is carried out both at a global and a regional scale. We attempt to 
examine whether globalization forces, deeper economic integration and swift transmission of knowledge flows around the world set in motion these kinds of forces that all countries can potentially be advantageous hosts to foreign investors and share the beneficial outcome with already charismatic milieus. It is our strong belief that in compliance with conventional convergence theory, it is more likely that we observe convergence-clubs, namely, convergence among countries belonging to the same group in terms of economic, political and/or institutional conditions.

\section{Data and Methodology}

\section{A. Data and Groups of Countries}

In our analysis we use annual data from 1980 to 2003 for FDI stocks per capita for a total of 35 countries. ${ }^{3}$ The list of all countries, along with some essential descriptive statistics, can be found in Table 1. The data we use were obtained from the United Nations Conference on Trade and Development and the World Development Indicators from the World Bank. We have grouped our full sample of countries in various groups adhering to certain development levels but also to similar institutional/integration levels, so as to be able to draw particular conclusions and policy implications. We then consider certain variations for each group. The groups are numbered consecutively from 1 to 11 (basic groups) and 12 to 20 (alternative variations) and their corresponding members are as follows:

1. Total: all 35 countries.

2. High Income OECD countries: Australia, Belgium-Luxembourg, Canada, France, Germany, Greece, Ireland, Japan, Korea Rep., Holland, Portugal, Spain, UK, US.

3. Top FDI recipients worldwide: Belgium-Luxembourg, France, Germany, Holland, UK, US.

4. Top FDI recipients in EU: Belgium-Luxembourg, France, Germany, Holland, UK.

5. Cohesion EU countries: Greece, Ireland, Portugal, Spain.

6. Accession EU countries of CEE: Czech Republic, Estonia, Hungary, Poland.

7. Enlarged EU: Groups 4, 5 and 6 above.

8. Asia and Oceania: Hong-Kong, India, Indonesia, Korea Rep., Singapore, Sri Lanka, Taiwan.

${ }^{3}$ Belgium and Luxembourg are used together, so the effective number of countries is 34 . 
Table 1. Descriptive Statistics for Annual Growth of FDI per capita

\begin{tabular}{|c|c|c|c|c|c|c|c|c|}
\hline \# & Country name & Abbreviation & $\mathrm{T}$ & Mean & Median & Std. Dev. & $r(1)$ & $\mathrm{g}$ \\
\hline 1 & ALGERIA & $\mathrm{AL}$ & 23 & 0.018 & -0.007 & 0.041 & 0.560 & 0.020 \\
\hline 2 & AUSTRALIA & $\mathrm{AU}$ & 23 & 0.099 & 0.082 & 0.165 & 0.746 & 0.082 \\
\hline 3 & BELGIUM & $\mathrm{BE}$ & 23 & 0.167 & 0.111 & 0.136 & 0.776 & 0.159 \\
\hline 4 & BRAZIL & BR & 23 & 0.031 & 0.030 & 0.060 & 0.730 & 0.030 \\
\hline 5 & CANADA & $\mathrm{CA}$ & 23 & 0.071 & 0.063 & 0.076 & 0.711 & 0.065 \\
\hline 6 & CHILE & $\mathrm{CH}$ & 23 & 0.052 & 0.074 & 0.455 & 0.861 & 0.103 \\
\hline 7 & CZECH REP. & $\mathrm{CZ}$ & 15 & 0.027 & 0.025 & 0.017 & 0.705 & 0.029 \\
\hline 8 & ESTHONIA & ET & 12 & 0.466 & 0.346 & 0.365 & 0.556 & 0.392 \\
\hline 9 & FRANCE & FR & 23 & 0.119 & 0.106 & 0.092 & 0.783 & 0.127 \\
\hline 10 & GERMANY & $\mathrm{DE}$ & 23 & 0.124 & 0.085 & 0.194 & 0.798 & 0.155 \\
\hline 11 & GREECE & GR & 23 & 0.053 & 0.106 & 0.211 & 0.584 & 0.039 \\
\hline 12 & HOLLAND & NL & 23 & 0.125 & 0.097 & 0.125 & 0.787 & 0.138 \\
\hline 13 & HONG KONG & HK & 23 & -0.016 & -0.028 & 0.134 & 0.670 & -0.010 \\
\hline 14 & HUNGARY & $\mathrm{HU}$ & 18 & 0.379 & 0.233 & 0.395 & 0.805 & 0.417 \\
\hline 15 & INDIA & $\mathrm{IN}$ & 23 & 0.165 & 0.134 & 0.112 & 0.775 & 0.176 \\
\hline 16 & INDONESIA & ID & 23 & 0.059 & 0.063 & 0.076 & 0.811 & 0.055 \\
\hline 17 & IRELAND & IE & 23 & 0.029 & 0.008 & 0.054 & 0.530 & 0.020 \\
\hline 18 & JAPAN & JP & 23 & 0.140 & 0.085 & 0.209 & 0.720 & 0.140 \\
\hline 19 & KOREA & KR & 23 & 0.146 & 0.106 & 0.089 & 0.769 & 0.153 \\
\hline 20 & MAURITIUS & MR & 23 & 0.140 & 0.097 & 0.124 & 0.806 & 0.153 \\
\hline 21 & MEXICO & MX & 23 & 0.112 & 0.115 & 0.141 & 0.661 & 0.095 \\
\hline 22 & MOROCCO & $\mathrm{MC}$ & 23 & 0.025 & 0.012 & 0.038 & 0.620 & 0.020 \\
\hline 23 & NIGERIA & NG & 23 & 0.072 & 0.056 & 0.057 & 0.809 & 0.074 \\
\hline 24 & PARAGUAY & PA & 23 & 0.036 & 0.061 & 0.128 & 0.888 & 0.052 \\
\hline 25 & POLAND & PL & 13 & 0.474 & 0.366 & 0.399 & 0.636 & 0.426 \\
\hline 26 & PORTUGAL & PT & 23 & 0.115 & 0.094 & 0.091 & 0.761 & 0.118 \\
\hline 27 & SINGAPORE & SG & 23 & 0.078 & 0.085 & 0.064 & 0.793 & 0.081 \\
\hline 28 & SPAIN & ES & 23 & 0.161 & 0.164 & 0.179 & 0.829 & 0.178 \\
\hline 29 & SRI LANKA & SL & 22 & 0.092 & 0.073 & 0.068 & 0.758 & 0.091 \\
\hline 30 & TAIWAN & TW & 23 & 0.069 & 0.070 & 0.115 & 0.826 & 0.086 \\
\hline 31 & UK & UK & 23 & 0.103 & 0.130 & 0.144 & 0.769 & 0.112 \\
\hline 32 & USA & US & 23 & 0.117 & 0.120 & 0.067 & 0.751 & 0.109 \\
\hline 33 & VENEZUELA & VE & 23 & 0.052 & 0.042 & 0.099 & 0.810 & 0.060 \\
\hline 34 & ZAMBIA & ZB & 23 & 0.056 & 0.040 & 0.071 & 0.830 & 0.070 \\
\hline
\end{tabular}

Notes: T denotes number of years, mean, median and std. dev. denote the statistics for the annual FDI growth, $r(1)$ is the autocorrelation coecient for the FDI levels and $\mathrm{g}$ is an estimate of annual growth from a trend regression.

9. Newly Industrialized Countries (NICs): Hong-Kong, Korea Rep., Singapore, Taiwan.

10. Africa: Algeria, Mauritius, Morocco, Nigeria, Zambia.

11. Latin America: Brazil, Chile, Mexico, Paraguay, Venezuela. 
12. Old EU members: Groups 4 and 5.

13. Cohesion countries excluding Ireland.

14. Cohesion countries excluding Ireland and Accession countries of CEE.

15. Countries at the middle income: Algeria, Brazil, Chile, Czech Republic, Estonia, Hungary, Indonesia, Mauritius, Mexico, Morocco, Paraguay, Poland, Sri Lanka, Venezuela.

16. Countries at the upper middle income: Chile, Czech Republic, Estonia, Hungary, Mauritius, Mexico, Poland, Venezuela.

17. Countries at the lower middle income: Algeria, Brazil, Indonesia, Morocco, Paraguay, Sri Lanka.

18. Africa excluding Nigeria and Zambia.

19. Africa (excluding Nigeria and Zambia) and Latin America.

20. Asia and Oceania with Japan.

The above groups can also be found concisely in Table 2, along with a corresponding ANOVA F-test for the equality of average FDI growth within each group. It is interesting to note that these $F$-tests indicate that there is substantial heterogeneity in the average FDI growth within each of the groups considered, with the exceptions of groups $3,4,11,19$ and possibly 13 . Note that both groups 3 and 4 correspond to high-income OECD countries that are among the top recipients of FDI. This observed heterogeneity in average growth rates can be used as an initial rough guide in the specication of our test regressions in the next section.

The groups were formed using the two criteria stated above: for the development one, we followed OECD classication for OECD countries and World Bank classication for the rest of economies ${ }^{4,5}$ from Asia, the Pacific, Latin America and South Africa. We initially test for the total of 35 countries in our sample. However, given the very different developmental, institutional and regional aspects of them, it would be more proper to split countries into sub-groups and check for

\footnotetext{
${ }^{4}$ Four groups are identified: high-income group with per capita GDP 120 and above, based on Purchasing Power Parity index values; high-middle income group with values between 100 and 120; low-middle income group with values between 50 and 99 and low income group with values less than 50 (OECD Comparative GDP Figures).

${ }^{5}$ These are classified as: low-income economies (Nigeria and Zambia), lower-middle income economies (Indonesia, Paraguay, Sri Lanka) and upper-middle income economies (Chile and Mauritius) (World Bank, Data and Statistics).
} 
Table 2. Composition of Groups and ANOVA F-tests

\begin{tabular}{llc}
\hline & & ANOVA \\
\hline Group Name & Group Composition & value \\
Total & All 35 countries & 0.000 \\
High Income OECD & AU, BE, CA, DE, ES, FR, GR, IE, JP, KR, NL, PT, & 0.045 \\
Top World & UK, US & 0.691 \\
Top EU & BE, DE, FR, NL, UK, US & 0.636 \\
Cohesion & BE, DE, FR, NL, UK & 0.014 \\
Accession & ES, GR, IE, PT & 0.002 \\
Enlarged EU & CZ, ET, HU, PL & 0.000 \\
Asia and Oceania & BE, CZ, DE, ES, ET, FR, GR, HU, IE, NL, PL, PT, UK & 0.000 \\
NIC & ID, IN, HK, KR, SG, SL, TW & 0.000 \\
Africa & HK, KR, SG, TW & 0.000 \\
Latin America & AL, MC, MR, NG, ZB & 0.755 \\
Old EU & BR, CH, MX, PA, VE & 0.028 \\
Cohesion w/out IE & BE, DE, ES, FR, GR, IE, NL, PT, UK & 0.099 \\
Cohesion and Accession & ES, GR, PT & 0.000 \\
Middle Income & AL, BR, CH, CZ, ET, HU, ID, MC, MR, MX, PA, PL, & 0.000 \\
Upper Middle Income & SL, VE & 0.000 \\
Lower Middle Income & AL, BR, ID, MC, PA, SL & 0.013 \\
Africa w/out NG and ZB & AL, MC, MR & 0.000 \\
Latin America and Africa & AL, BR, CH, MC, MR, MX, PA, VE & 0.252 \\
Asia and Oceania w/ Japan & ID, IN, HK, JP, KR, SG, SL, TW & 0.000 \\
\hline
\end{tabular}

Notes: country name abbreviations are given in table 1; the ANOVA $p$-value column corresponds to the p-value of the ANOVA $F$-test for equality of average FDI growth within each group.

conditional convergence.

The first group we consider includes all high-income OECD countries. These countries share common advancement characteristics, such as demand for more elaborated and advanced products, a developed and well structured industrial base and infrastructure, high levels of skills, etc. The working hypothesis here would be that they all receive approximately the same FDI in per capita basis, thus, their foreign capital would converge if we are to agree on the role of foreign capital as a third factor of production, and a signicant one for growth. We have grouped countries that belong to lower levels of income, either upper middle or lower middle income according to their World Bank classification. The argument here would be the same as for the grouping of high-income OECD countries. The next group includes only those countries from the high-income OECD group that are registered in the 
list of the top recipients of FDI, i.e., Belgium-Luxemburg, Germany, France, Netherlands, the UK and the US. Obviously, we would expect convergence in this group of countries as well. A similar argument should hold for the group of the top EU recipients, when we exclude the US.

However, the development level is only one aspect of the story: when taken alone, it does not guarantee convergence in per capita foreign capital stocks, if one were to take regional and institutional features into consideration. An example would be Australia, which is located far away from the majority of all other highincome countries. So, we went on splitting the countries into more groups while keeping in mind these differences. Another group contains the EU cohesion countries, Greece, Ireland, Portugal and Spain: these countries have been receiving large sums from the EU for the last two decades in order to upgrade their developmental base. We then consider the new EU member states of Central and Eastern Europe, Czech Republic, Estonia, Hungary and Poland, that were among the first to begin liberalization back in the nineties and they are of particular attractiveness to foreign investors.

A group of relative importance corresponds to countries in Africa. This area has been receiving increased amounts of FDI registering an increase of $39 \%$ in 2003 ! (WIR, 2005). In addition, there has been a wave of FDI-friendly measures and initiatives at the national, regional and global levels to attract more FDI into the region. Algeria and Mauritius for example have simplified their regulation, while Algeria and Zambia are in the process of undertaking Investment Policy Reforms. A similar group is that for countries in Latin America. This region has registered an upsurge in FDI inows in 2004 after half a decade of economic stagnation. FDI has received favorable treatment in most Latin American countries as part of a broader free-market and liberalization policy since the early 1990s that included various forms of preferential treatment for foreign investors. Finally, we have examined groups for countries in Asia and Oceania, including a separate group for the NIC countries, Hong-Kong, Taiwan, Korea and Singapore.

The rest of our groups are variations on the above and serve both as extensions and as robustness checks in our analysis. Among others, we examine the effects of combining the cohesion countries with the accession countries with Ireland excluded, we combine the upper middle and lower middle income groups together, we exclude the poorest economies of Nigeria and Zambia from the group of African countries, we include Japan in the group of countries in Asia and Oceania and we combine the countries from Africa and Latin America. 


\section{B. Econometric Methodology}

Numerous convergence studies have used a variety of different approaches for assessing the degree of convergence. Representative of the methods usually used are those of Bernand and Durlauf (1995, 1996), Ben-David (1996, 1997), Kočenda and Papell (1997), Kočenda (2001) and Kutan and Yigit (2004). In all of those the approach taken is to test for, and estimate the convergence coefficient from, a panel unit root model using a suitable autoregressive approximation. The autoregressive formulation is based on essentially two conditions, one for the evolution of effective per capita output around the steady state and the other on the evolution of effective labor. For a textbook derivation and review of such a model see Hayashi (2000, ch. 5), from which the following summary is adapted. Let $Y_{i}(t)$ denote output for country $i, L_{i}(t)$ denote labor and $A_{i}(t)=A_{i}(0) \exp (g t)$ denote technical progress that evolves at a deterministic growth rate of $\mathrm{g}$; also denote by $q_{i}(t) \stackrel{\text { def }}{=}$ $Y_{i}(t) /\left[A_{i}(t) \cdot L_{i}(t)\right]$ the effective per capita output. Then evolution of $q_{i}(t)$ around the steady state $q^{*}$ is given as:

$$
\frac{d \log q_{i}(t)}{d t}=\lambda\left[\log q^{*}-\log q_{i}(t)\right]
$$

dt where $\lambda$ denotes the speed of convergence. Using the definition of $q_{i}(t)$ at two discrete time instances $t_{m}$ and $t_{m-1}$ one can derive the autoregressive approximation that most studies use in assessing convergence, where we now take into account the panel structure of the dataset:

$$
y_{i m}=\alpha_{i}+\alpha_{m}+\rho y_{i, m-1}+e_{i m}
$$

where now $y_{i m} \stackrel{\text { def }}{=} Y_{i m} / L_{i m}, \alpha_{i}$ stands for a term capturing individual heterogeneity and is a function of $q^{*}$ and $A_{i}(0), \alpha_{m} \stackrel{\text { def }}{=} \rho \cdot\left(t_{m}-t_{m-1}\right)$ stands for a term that captures the growth of technical progress, and $e_{i m}$ is the corresponding error term. The coefficient $\rho \stackrel{\text { def }}{=} \exp \left[-\lambda\left(t_{m}-t_{m-1}\right)\right]$ estimates the speed of convergence.

There are several points that need to be raised when one considers using the above conceptual framework. First of all, notice that the speed of convergence is nothing more than the degree of temporal persistence of output around the steady state. Then, note that in equation (2) above the $\rho$ coefficient does not exhibit cross-sectional variation; any cross-sectional variation (if present) is captured by the $\alpha_{i}$ term. Depending on how one treats the presence of cross-sectional variation one can 
obtain drastically different results by applying different methods. Next, consider the case where the convergence hypothesis holds and thus $\rho<1$. It is well known that standard panel methods for estimating dynamic coefficients fail in this case, when the time dimension is small. If this is coupled with the fact that the panel unit root tests used in previous studies usually assume that both the cross-sectional and the time dimension of the panel grows large for deriving asymptotic results ${ }^{6}$, one can easily conjecture that the estimates of the convergence coefficients from the panel unit root tests may not necessarily be the "appropriate" ones. Even if they are, in none of these studies can we find evidence on the robustness of their estimates by comparing them to different estimation methods. We do so here by providing three different types of estimates for the speed of convergence: the estimates from panel unit root tests, the estimates from dynamic panel regressions estimated by the Generalized Method of Moments (GMM), and the estimates from a much simpler panel model that is based on the very definition of our dependent variable. We thus consider next the actual models and methods that we employed in our paper.

Our starting point for providing a measure for the speed of convergence rests on our initial comment in the previous paragraph: the speed of convergence is a measure of temporal persistence. Is there a simple way of capturing this without resorting to panel unit root tests? Let us now denote by $Y_{i}(t)$ the level of FDI stocks of country $i$ and by $L_{i}(t)$ the population. For the latter we can easily get away with the assumption that it grows deterministically at a rate of $\pi$, say $L_{i}(t) \stackrel{\text { def }}{=} L_{i}(0)$ $\exp (\pi t)$. For the former we make the simplifying assumption that it grows stochastically around a deterministic trend as $Y_{i}(t) \stackrel{\text { def }}{=} Y_{i}(0) \exp [g t+u(t)]$, where $u(t)$ denotes the continuous time analog of a first-order autoregression with parameters $\rho$ and $\sigma$, that are independent of time. ${ }^{7}$

Dening the log of per capita FDI as $y_{i}(t)$ is is straightforward to see that:

$$
y_{i}(t)=y_{i}(0)+(g-\pi) t+u(t)
$$

If we now take the discrete time version of equation (3) above, and also account

\footnotetext{
${ }^{6}$ Correspondingly, in most of these studies the authors perform Monte Carlo simulations to determine critical values based on the characteristics of their datasets.

${ }^{7}$ Formally we have that $u(t)$ is dened by the diffusion $d u(t)=\lambda u(t) d t+\sigma d W(t)$, where $W(t)$ is standard Brownian motion. Then, $u(t)$ can be expressed as $u(t)=\rho u(t-1)+S(t)$, where we have $\rho \stackrel{\text { def }}{=} \exp (\lambda)$ and $S(t)$ is a stochastic integral. Note the similarities between our derivation and that leading to equation (2).
} 
for the panel nature of the dataset, we can write the following estimable version:

$$
y_{i m}=\alpha_{i}+\beta t_{m}+u_{i m}
$$

where $\alpha_{i} \equiv y_{i}(0)$ and $\beta \equiv(g-\pi)$. Note that we can also express equation (4) in practically the same form as equation (2):

$$
y_{i m}=\alpha_{i}+a_{m}+\rho y_{i, m-1}+\varepsilon_{i m}
$$

where $a_{i}=\rho \beta+(1-\rho) \alpha_{i}$ and $a_{m}=(1-\rho) \beta t_{m}$ denote the cross-sectional and time-specic effects, and where $\varepsilon_{i m}$ denotes the new error term. Note that equations (2), (4) and (5) should essentially estimate the same thing as the convergence coefficient. However, the estimation of equation (4) is substantially easier that the estimation of equations (2) or (5), it has the added advantage of the (economically) interpretable trend differential $(g-\pi)$ and can take into account cross-sectional heterogeneity in many standard ways that are (usually) not accounted for when panel unit root tests are used. As we will later see in the results section, this approach gives results that are in agreement both with the unit root tests and the results using GMM, and in our opinion can complement the standard methods and provide for more robust results.

Equation (4) was estimated by generalized least squares (GLS), with fixed effects and cross-section weights to account for heterogeneity in both the means and the variances; significance of estimates was based on a robust covariance matrix. Equations (2) and (5) were estimated using the generalized method of moments (GMM) and with the cross-sectional means removed in each period. ${ }^{8}$ The heterogeneity was removed using orthogonal deviations (Arellano and Bover, 1995) and the smallest possible number of dynamic instruments (two or three, based on which choice minimized the std. error of the regression); we do this as we are going to estimate only one parameter, the convergence coefficient $\rho$. Signicance of estimates was based again in a robust covariance matrix. For all equations estimated by GMM we could not reject the hypothesis of instrument validity based on the $J$-test for

${ }^{8}$ That is, the dependent variable for estimating equation (4) was $y_{\text {im }}$ while the dependent variable for estimating equations (2) or (5) was $y_{i m}-\bar{y}_{m}$, where $\bar{y}_{m} \stackrel{\text { def }}{=} n^{-1} \sum_{i=1}^{n} y_{i m}$. Note that the removal of the crosssectional means does not remove the heterogeneity that may be present in the model, they will only remove the constant. This is important for applying GMM methods. 
overidentication. Both the GLS and GMM estimation frameworks are standard and details can be found, for example, in Hayashi (2000).

In addition to the above two estimation methods of equations (2), (4) and (5) we used two types of panel unit root tests for assessing convergence and for providing a third alternative estimator of the convergence coecient. We applied the test of Levin, Lin and Chu (2002 -LLC hereafter) with fixed effects and the test of Im, Pesaran and Shin (2003 -IPS hereafter) also with fixed effects. The first test assumes that a common unit root is present in all cross-sections while the second test assumes that different unit root processes are present in individual crosssections. The generic form of the test equations is given by:

$$
\Delta y_{i m}=\alpha_{i}+\theta_{i} y_{i m}+\sum_{j=1}^{p_{i}} \theta_{i j} \Delta y_{i, m-j}+\varepsilon_{i m}
$$

where $\theta_{i} \stackrel{\text { def }}{=} \rho_{i}-1$. The null hypothesis for the LLC test is $\mathrm{H} 0: \theta_{i}=\theta=0$ while the null hypothesis for the IPS test is $H_{0}: \theta_{i}=0$ for all $i$ - for both tests we see that the null hypothesis is that of a unit $\operatorname{root}(\mathrm{s})$. Therefore, rejection of the null hypothesis corresponds to convergence. A common estimate of the convergence coefficient (as suggested by the theory) is only given by the LLC test; on the other hand, the IPS test may be better able to capture the potential differences between countries when testing for the presence of stochastic trends. Both the LLC and the IPS test were conducted using the Bayesian information criterion for selecting the optimal lag lengths of the test regression. We omit additional details about these tests as they are widely available in the cited references at the beginning of this section; a textbook exposition can also be found in Baltagi (2005, ch. 12).

Finally, for all three estimation methods of the convergence coefficient we computed the implied half-lives. In the context of an autoregressive specication the half life corresponds to the number of periods required for the impulse response to dissipate by half, after a unit shock. It is a nonlinear function of the estimated parameter(s) of the specication and, as such, is an alternative measure of persistence. For an autoregressive model of order one it has the closed form solution:

$$
h \stackrel{\text { def }}{=}\left\{\begin{array}{cc}
\ln (0.5) / \ln (\rho) & \text { if } \rho<1 \\
\infty & \text { otherwize }
\end{array}\right\}
$$

For higher order models once can use, as an approximation, the above formula for the sum of the autoregressive coecients. For all of the models we consider, an estimate of the half-life coefficient is obtained then directly from the estimate of $\rho^{9}$. 
In our context, the interpretation of the half-life estimates is the number of years required to close the convergence gap in half.

\section{Results and Discussion}

The testing and estimation results are presented in Tables 3 and 4. In Table 3 we present the results from the test equation (6) on the panel unit root tests; the table entries give the $p$-value of the tests and the estimates of the convergence coefficient and the implied half-lives from the LLC test. In Table 4 we present the results from the estimation of equations (2), (4) and (5); the table entries give the estimates of

Table 3. Panel Unit Root Tests, Convergence Coecients and Implied Half-Lives

\begin{tabular}{|c|c|c|c|c|}
\hline \multirow[b]{2}{*}{ Group Name } & \multicolumn{3}{|c|}{ LLC } & \multirow{2}{*}{$\begin{array}{c}\text { IPS } \\
\text { p value }\end{array}$} \\
\hline & p-value & $\rho$ & $\mathrm{h}$ & \\
\hline Total & 0.016 & 0.930 & 9.499 & 0.918 \\
\hline High Income OECD & 0.020 & 0.935 & 10.335 & 0.523 \\
\hline Top World & 0.031 & 0.741 & 2.309 & 0.006 \\
\hline Top EU & 0.009 & 0.703 & 1.968 & 0.001 \\
\hline Cohesion & 0.090 & 0.944 & 12.136 & 0.862 \\
\hline Accession & 0.000 & 0.810 & 3.295 & 0.001 \\
\hline Enlarged EU & 0.000 & 0.793 & 2.991 & 0.000 \\
\hline Asia and Oceania & 0.959 & 0.992 & 82.985 & 0.938 \\
\hline NIC & 0.648 & 0.991 & 72.847 & 0.863 \\
\hline Africa & 0.005 & 0.940 & 11.164 & 0.129 \\
\hline Latin America & 0.636 & 0.855 & 4.419 & 0.508 \\
\hline Old EU & 0.040 & 0.927 & 9.209 & 0.275 \\
\hline Cohesion w/out IE & 0.515 & 0.931 & 9.695 & 0.846 \\
\hline Cohesion and Accession & 0.000 & 0.810 & 3.293 & 0.000 \\
\hline Middle Income & 0.005 & 0.900 & 6.567 & 0.400 \\
\hline Upper Middle Income & 0.380 & 0.886 & 5.721 & 0.681 \\
\hline Lower Middle Income & 0.085 & 0.920 & 8.332 & 0.398 \\
\hline Africa w/out NG and ZB & 0.046 & 0.961 & 17.468 & 0.693 \\
\hline Latin America and Africa & 0.151 & 0.930 & 9.579 & 0.501 \\
\hline Asia and Oceania w/ Japan & 0.916 & 0.984 & 41.795 & 0.979 \\
\hline
\end{tabular}

Notes: LLC corresponds to the Levin, Lin and Chu panel unit root test that assumes a common unit root process; IPS corresponds to the Im, Pesharan and Shin panel unit root test that assumes individual unit root processes; both tests performed using fixed effects; $p$-value is the $p$-value of the corresponding test, $\rho$ is the implied estimate of the convergence coefficient and $h$ is the implied half-life (in years) computed as $\ln (0.5) / \ln (\rho)$.

${ }^{9}$ For a recent technical overview about the estimation of half-lives see Kim et al. (2006). 
the convergence coecient and the implied half-lives from GLS and GMM-based models - for the GLS-based model we also report the estimate of the trend differential.

We begin our discussion with the results from the panel unit root tests. The LLC test rejects the null hypothesis of a common unit root at the $5 \%$ level for all groups except the following: the Asia and Oceania group, the Asia and Oceania group with Japan, the Latin America group, the combined Africa and Latin America group, the NIC group, the cohesion countries without Ireland group and the upper middle income group. For these groups the IPS test also does not reject the null hypothesis of individual unit roots. The estimates of the implied half-lives range from about 4.5 years for the Latin America group to over 80 years for the Asia and

Table 4. GLS/GMM Estimates of the Convergence Coecients and Implied Half-Lives

\begin{tabular}{|c|c|c|c|c|c|}
\hline \multirow[b]{2}{*}{ Group Name } & \multicolumn{3}{|c|}{ GLS } & \multicolumn{2}{|c|}{ GMM } \\
\hline & $\beta \equiv \mathrm{g}-\pi$ & $\rho$ & $\mathrm{h}$ & $\rho$ & $\mathrm{h}$ \\
\hline Total & 0.096 & 0.934 & 10.144 & 0.917 & 8.015 \\
\hline High Income OECD & 0.131 & 0.942 & 11.521 & 0.825 & 3.599 \\
\hline Top World & 0.135 & 0.786 & 2.885 & 0.771 & 2.665 \\
\hline Top EU & 0.140 & 0.720 & 2.110 & 0.850 & 4.274 \\
\hline Cohesion & 0.153 & 0.961 & 17.451 & 0.919 & 8.249 \\
\hline Accession & 0.198 & 0.724 & 2.148 & 0.826 & 3.620 \\
\hline Enlarged EU & 0.144 & 0.892 & 6.086 & 0.875 & 5.170 \\
\hline Asia and Oceania & 0.179 & 0.980 & 34.310 & 0.982 & 39.162 \\
\hline NIC & 0.117 & 0.965 & 19.343 & 0.980 & 33.532 \\
\hline Africa & 0.083 & 0.939 & 11.001 & 0.954 & 14.830 \\
\hline Latin America & 0.060 & 0.877 & 5.277 & 0.771 & 2.671 \\
\hline Old EU & 0.149 & 0.945 & 12.205 & 0.936 & 10.427 \\
\hline Cohesion w/out IE & 0.141 & 0.917 & 7.952 & 0.923 & 8.612 \\
\hline Cohesion and Accession & 0.141 & 0.881 & 5.465 & 0.910 & 7.341 \\
\hline Middle Income & 0.070 & 0.921 & 8.452 & 0.867 & 4.876 \\
\hline Upper Middle Income & 0.119 & 0.866 & 4.825 & 0.881 & 5.448 \\
\hline Lower Middle Income & 0.045 & 0.876 & 5.214 & 0.833 & 3.798 \\
\hline Africa w/out NG and ZB & 0.250 & 0.981 & 36.644 & 0.961 & 17.631 \\
\hline Latin America and Africa & 0.088 & 0.943 & 11.849 & 0.909 & 7.261 \\
\hline Asia and Oceania w/ Japan & 0.106 & 0.975 & 27.015 & 0.992 & 86.899 \\
\hline
\end{tabular}

Notes: GLS and GMM denote the corresponding estimation method; $\rho$ denotes the estimate of the convergence coecient; $\beta \equiv g-\pi$ denotes the estimate of the trend/annual growth within a group; $h$ is the implied half life (in years) computed as $\ln (0.5) / \ln (\rho)$; GLS estimation done using fixed eects and groups weights; GMM estimation done via orthogonal deviations; all estimates signicant at the $5 \%$ level except those in italics. 
Oceania group. For the rest of the groups, for which the LLC test rejects the null hypothesis of a common unit root, the estimates of the implied half-lives range from about 2 years for the top FDI recipients in EU group to about 18 years for the Africa without Nigeria and Zambia group. The mean and median half-life estimates for the converging groups are 7.1 and 6.6 years respectively; the corresponding mean and median values for the non-converging groups are 27 and 10 years respectively. These broad results are (statistically) palatable, as the mean and median half-lives of the converging groups are lower than those of the nonconverging groups, and the range of the half-lives for the converging groups is well within the range of the half-lives for the non-converging groups. On the other hand, the IPS test does not always reject the presence of individual unit roots in the series. It does reject though for some interesting groups: the two top FDI recipient groups, the accession countries group, the cohesion countries plus the accession countries group and the enlarged EU group. For these groups both unit root tests agree on the presence of convergence. The mean and median values of the estimated half-lives for these ve groups are about 3 years each (obtained from the LLC estimates).

Although the two types of tests do not uniformly agree on their outcomes, we see that a rough classication of the groups emerges. The two top FDI recipient groups have the highest speed of convergence (estimated $\rho$ below 0.75 ), followed by the three EU groups (enlarged EU, cohesion countries and accession countries and accession countries groups - estimated $\rho$ about 0.8 ), followed by the Latin America group, and the upper middle and middle income groups (estimated $\rho$ about 0.9 ). All other groups have estimated convergence coefficients above 0.9 that correspond to half-lives of over 8 years. It is interesting to note that the speed of convergence for groups like the high-income OECD group, the cohesion countries group or the NIC group are higher and have estimated half-lives of over 10 years. For the grand grouping of all countries together we find a convergence coefficient of 0.93 with an estimated half-life of about 9 to 10 years; taken at face value these last estimates would tell us that the convergence gap would close in less than a generation from today, making the strong assumption of no structural changes in the interim.

Given our discussion on the previous section, we next discuss our estimation results from the models of equations (4) and (5) via GLS and GMM. The results presented in table 4 are meant to be both supportive to the results just discussed but also more robust estimates of the speed of convergence. It is interesting to begin by 
noting that for 15 out of the 20 groups considered the estimates of $\rho$ between the two methods have absolute differences less than $5 \%$, that is $\left|\rho_{G L S}-\rho_{G M M}\right|<0.05$. It appears that both methods deliver relatively comparable results and is instructive to rank the groups according to their speed of convergence (equivalently, their halflife estimates) for both methods - we could then compare these results with the results from the panel unit root tests. Ranking the groups using the half-life estimates from the GLS method we see that there is quite close an agreement with the results from the panel unit root tests. Top speed of convergence (estimated $\rho$ below 0.9) is again exhibited by the same groups from the panel unit root tests, with the exception of having the lower middle income group having now an estimated half-life of about 5 years. Ranking the groups using the half-life estimates from the GMM method does not change the general result we had so far, although it does change the relative position of the countries with top convergence speed. The most notable change is that now the high-income OECD group is ranked third with an estimated half-life of about 4 years. All in all, we find remarkable agreement across methods of estimating the speed of convergence. From the point of view of parsimony and (conceptual and practical) simplicity the GLS estimation results appear to be preferable. The statistical cohesion we have across methods is clearly very useful in the economic interpretation of our results.

With regards to the EU groups, it appears that, as expected, the top recipients should converge in their foreign capital stocks in about 8.5 years; they already are the major recipients of FDI, with the UK being way ahead. When accounting for the old members of the EU, i.e., the top recipients and the cohesion countries of Greece, Portugal, Spain and Ireland, the speed of convergence slows down with a longer half-life. Cohesion countries seem disparate on their own though: although they are usually (officially) classified together in terms of developmental similarities and structural problems, for which they receive funds from the EU, we see that their attractiveness in FDI is not the same. This can possibly be explained by the inability of Greece to attract foreign investors and the low levels of FDI received by Portugal. Spain and Ireland have done better through the years. On the other hand, the accession countries of CEE seem more similar on those grounds. An interesting question would be to check for the cohesion countries and the accession ones given the current debate for the redirection of FDI from South to North: our results point to convergence in about 15 years, clearly not a short period. Nevertheless, as a whole, the enlarged EU gives an estimate of about 5 years of half-life. ${ }^{10}$ 
Groupings with countries at similar stages of development, namely, high-income OECD, middle income, upper-middle income and lower-middle income, have faster convergence estimates than the average. This is in full conformity with the theory: since they belong to the same developmental group, they share common characteristics in terms of infrastructure, skills availability, etc., thus they would be equally attractive to foreign investors (a potential aspect of dierentiation would be the FDI policy stance).

Among the other groups, the fast convergence for the Latin America group is also in accordance with empirical facts, i.e., countries included in this group enjoy increasing levels of inward FDI. Africa, on the other hand, although is a particularly attractive region lately, indicates appreciable differences among its members. This can be attributed to the distinct disparities among them as, for example, the oilproducing countries vis-a-vis the rest (Nigeria is a major oil-producing country although it is a classied as a low income country). When taken together, Africa and the countries of Latin America have an average half-life of about 10 years. This estimate is between the individual estimates for the two groups separately and is probably evidence toward the rising attractiveness of both regions to foreign investors primarily for their growth prospects and adoption of particular FDI friendly measures.

The most heterogeneous groupings belongs to Asia and Oceania, both with and without Japan, and the same holds for the NICs. Their estimates of the speed of convergence are above 0.95 with correspondingly high half-lives, possibly indicating divergence. This can be attributed to particular attractiveness of some of those countries but not the region as a whole, at least for the time being. Conforming to the 2005 WIR, $92 \%$ of FDI is concentrated in only a small number of the countries in this region (the majority is directed towards Hong-Kong and Singapore, with Korea, Taiwan and India following far behind).

The above main points may be of particular importance to supranational, national and even regional policy making agencies. Countries belonging to similar developmental and/or institutional/integration categories will probably converge within the time frame of a generation. Given that globalization tendencies alter economic forces, and thus the comparative advantage of nations and regions, attention should be drawn to less advanced economies that lack inducements which would pull

\footnotetext{
${ }^{10}$ We should note that results could differ from what we currently have should we had included other countries, for example Latvia or the Slovak Republic which receive much less FDI.
} 
large amounts of FDI and reap the benefits associated with it. Though FDI is only one aspect of globalization, our results are indicative of the formation process of a global economic landscape and are even more clear for regions such as the EU that aim at a deeper economic integration.

Our overall results point to convergence of foreign capital stocks, hence to dispersion forces of industrial activity at this point of time, for most of the groups we considered. According to NEG predictions, this indicates that European Integration has moved below the intermediate range of values of trade freeness that favor centripetal forces to lower trade costs. Consequently, results here are in accordance with Brü lhart and Torstensson (1996) who predicted a fall in the signicance of concentration since the eighties. With respect to the global economy, as represented here by our sample of 35 countries, our results point to somewhat slower convergence, with an estimated half-life of about 10 years. This may imply that globalization has reached a stage where differences in the prices of immobile goods and factors take over, thus industry spreads to less developed regions (Ottaviano and Puga, 1997). This is evident from increasing FDI flows to Africa due to high prices of minerals platinum, coppers, diamonds, gold and particularly oil-along with the consequent improved protability of investment in natural resources (WIR, 2005). Nevertheless, there are still differences of the speed of convergence between different groups which make it preferable to talk about "convergence clubs" and should make us cautious when approaching a definitive answer about the validity of the NEG theory. The long time periods for closing existing gaps make us suspicious of what the industrial structure will be during this period following globalization forces and rapid technological developments. Will complete integration take place across countries of Regional Agreements and between regions of the global economy? Our empirical evidence suggests that groups of countries which manage to overcome inherent difficulties can surpass countries that were previously forging ahead.

\section{Concluding Remarks}

In this paper we attempted to assess the validity of the NEG predictions on the tendencies of polarization of economic activity to particular locales creating thus a "core-periphery" pattern, both at a large scale entailing entire regions down to a thin scale regarding agglomeration of particular industry sectors. Based on that, as globalization forces intensify and the flow of people, capital, knowledge etc. is becoming easier and faster, there is a possibility that production would tend to 
concentrate in large markets beneting the host milieus and creating virtuous cycles. Under this perspective, the theory is of particular importance to FDI patterns since this is perceived to consist an additional input (explicitly or implicitly) in the production function of countries transferring technology, skills, advanced management techniques, etc. Bearing in mind the NGT advocates suggesting constant or increasing returns in production due to this particular role of capital, the question posed herein is of primary concern as FDI allocation is likely to aect the growth paths of nations.

Using both the standard approach of assessing convergence and offering a small novelty for estimating the convergence speed, we examined whether there is any evidence of convergence of FDI stocks per capita worldwide and regionally. Results are indicative of convergence tendencies contrary to the "core-periphery" pattern. This may imply that we have possibly reached a state of lower trade costs that favor dispersion forces according to the NEG theory. However, a closer look at our results suggests that we need to be more cautious when evaluating the theory, since there appear to be differences in the common steady state of alternative groups of countries. This rather suggests the existence of "convergence" clubs, according to conventional convergence theory, i.e., convergence of countries to different steady states according to their groupings. This is also in line with the notion that results are subjective to groupings.

Our line of research may be extended to a thinner level of analysis to study concentration tendencies of higher value added activities (that are the ones with increasing returns) versus lower value added activities across and within nations and regions so that we can draw more precise conclusions on the validity of the NEG theory.

\section{Acknowledgments}

An earlier version of this paper was presented at the 2005 Conference of the European Economic and Finance Society at Coimbra, Portugal. We would like to thank the conference participants for useful comments and suggestions. We would also like to thank an anonymous referee for constructive criticisms that improved the content and presentation of our paper. All remaining errors are ours.

Received 16 May 2005, Accepted 31 July 2006 


\section{References}

Aghion, P. and P. Howitt (1992). A Model of Growth through Creative Destruction, Econometrica, 60(2), 323-51.

Arellano, M., and O. Bover (1995). Another Look at the Instrumental Variables Estimation of Error-components Models, Journal of Econometrics, 68, 29-51.

Baltagi, B. H. (2005). Econometric Analysis of Panel Data, 3rd. edition, Hoboken, NJ: John Wiley \& Sons.

Ben David, D. (1996). Trade and Convergence among Countries, Journal of International Economics, 40, 279-298.

Ben David, D. (1997). Convergence Clubs and Diverging Economies, mimeo, Tel Aviv University.

Bengoa, M. and B. Sanchez Roles (2003). Foreign Direct Investment, Economic Freedom and Growth: New Evidence from Latin America, European Journal of Political Economy, 19, 529-545.

Bernard, A., and S. Durlauf (1995). Convergence in International Output, Journal of Applied Econometrics, 10, 97108.

Bernard, A., and S. Durlauf (1996). Interpreting tests of the convergence hypothesis, Journal of Econometrics, 71, 161173.

Borenstein, E., J. De Gregorio, and J.W. Lee (1998). How does Foreign Direct Investment Aect Economic Growth?, Journal of International Economics, 45, 115-135.

Braconier, H. Ekholm, K. and K. Knarvik (2001). In Serach of FDI Transmitted R\&D Spillovers: A Study Based on Swedish Data, Weltwirchaftliches Archiv, 137(4), 644665.

Brū lhart M. and J. Torstensson (1996). Regional Integration, Scale Economies and Industry Location in the European Union, Centre for Economic Policy Research, Discussion Paper, No. 1435.

Dinopoulos, E. and P. Segerstrom (2005). Multinational Firms and Economic Growth, University of Florida, Department of Economics.

Dinopoulos, E. and P. Segertsrom (2004). A Sschumpetarian Model of Protection and Relative Wages, American Economic Review, 89, 450-472.

Fujita, M. and J. F. Thisse (1996). Economics of Agglomerations, Journal of the Japanese and International Economies, 10, 339-378.

Grossman, G. M. and E. Helpman (1991). Quality Ladders and Product Cycles, The Quarterly Journal of Economics, 106(2), 557-86.

Hanson, G. H. (1996). Economic Integration, Intraindustry Traden and Frontier Regions, European Economic Review, 40, 941-949.

Hanson, G. H. (1997a). Localization Economies, Vertical Organisationn and Trade, American Economic Review, 87, 1266-1278.

Hanson, G. H. (1997b). Increasing Returns, Trade and the Regional Structure of Wages, Economic Journal, 107, 113-133. 
Hayashi, F. (2000). Econometrics, Princeton: Princeton University Press.

Helpman, E. (1984). A Simple Theory of International Trade with Multinational Corporations, Journal of Political Economy, 92, 451-477.

Helpman, E. and P. Krugman (1985). Market Structure and International Trade, MIT Press.

Horstmann, I. and J. R. Markusen (1987). Strategic Investments and the Development of Multinationals, International Economic Review, 28(1), 109-121.

Im, K., H. Pesaran and Y. Shin (2003). Testing for unit roots in heterogeneous panels, Journal of Econometrics, 115, 5374.

Kim, J. H., P. Silvapulle and R. J. Hyndman (2006). Half-Life Estimation based on the Bias-Corrected Bootstrap: A Highest Density Region Approach, mimeo.

Kottaridi, C. (2005). The Core-Periphery Pattern of FDI-led-Growth and Production Structure in the EU, Applied Economics, 37, 99-113.

Koč enda, E. (2001). Macroeconomic Convergence in Transition Countries, Journal of Comparative Economics, 29, 1-23.

Kočenda, E. and Papell, D. (1997). Ination Convergence within the European Union: A Panel Data Analysis, International Journal of Finance and Economics, 2, 189198.

Krugman, P. (1979). A Model of Innovation, Technology Transfer and the World Distribution of Income, Journal of Political Economy, 87(2), 253-266.

Krugman, P. (1981). Intra-Industry Specialization and the Gains From Trade, Journal of Political Economy, 89(5), 959-973.

Krugman, P. (1991). Increasing Returns and Economic Geography, Journal of Political Economy, 99(3), 483-499.

Krugman, P. (1993). On the Relationship between Trade Theory and Location Theory, Review of International Economics, 1(2), 110-122.

Krugman, P. (1995). Innovation and Agglomeration: Two Parables Suggested by City Size Distribution, Japan and the World Economy, 7(4), 371-390.

Kutan, A. and T. Yigit (2004). Nominal and real stochastic convergence of transition economies, Journal of Comparative Economics, 32, 23-36.

Levin, A., C. F. Lin, and C. Chu (2002). Unit Root Tests in Panel Data: Asymptotic and Finite-Sample Properties, Journal of Econometrics, 108, 1-24.

Lucas, R. (1988). On the Mechanics of Economic Development, Journal of Monetary Economics, 22, 3-42.

Markusen, J. R. (1984). Multinationals, Multi-Plant Economies and the Gains From Trade, Journal of International Economics, 16, 205-226.

Markusen, J. R. and A. J. Venables (1988). Multinational Firms and the New Trade Theory, Journal of International Economics, 46(2), 183-203.

Markusen, J. R. and A. J. Venables (2000). The Theory of Endowment, Intra-Industry and Multinational Trade, Journal of International Economics, 52(2), 209-234.

Martin, P. and G. I. P. Ottaviano (1996). Growth and Agglomeration, CEPR Discussion Paper, 1529.

Ottaviano, G. and I.P. Puga (1997). Agglomeration in the Global Economy: a Survey of 
the New Economic Geography, World Economy, 21, 707-731.

Rivera-Batiz, L. A. and Romer, P. M. (1991). Economic Integration and Endogenous Growth, The Quartely Journal of Economics, 106(2), 531-555.

Quah, D. T. (1996). Regional Convergence Clusters Across Europe, European Economic Review, 40, 951-958.

Rebelo, S. (1991). Long Run Policy Analysis and Growth, Journal of Political Economy, 99, 500-521.

Romer, P.M. (1986). Increasing Returns and Long Run Growth, Journal of Political Economy, 94, 1002-1038.

Soci, A. (2003). FDI and the Process of European Integration: A Brief Overview, Journal of Economic Integration 18(4), 642-660.

Venables, A. (1996). Lecture Notes in International Trade and Imperfect Competition, Working Paper 463, Industrial Institute for Economic and Social Research.

World Investment Report (2004). The Shift towards Services, United Nations Conference on Trade and Development, United Nations.

Zhang, K.H. (1999). Foreign Direct Investment and Economic Growth: Evidence from Ten East Asian Economies, Economia Internazionale, 52(4), 517-535. 